\title{
Marcadores moleculares associados ao câncer de mama não metastático*
}

\author{
Molecular markers associated with node negative breast cancer
}

\author{
Daniela de Melo e Silva', Vera Aparecida Saddi² e Euza Guimarães Momotuk ${ }^{3}$
}

\section{Resumo}

0 câncer de mama é considerado a mais freqüente neoplasia que acomete mulheres em todo o mundo. No Brasil, representa a primeira neoplasia em incidência na mulher, sendo que a maioria dos casos relatados encontra-se na região Sul (67\%). Recentemente tem ocorrido um grande interesse na identificação de marcadores moleculares de valor prognóstico. N este trabalho, tanto a proteína p53 quanto o produto do oncogene c-erbB-2 foram avaliados em 61 pacientes com câncer de mama sem comprometimento axilar. Tais pacientes foram diagnosticadas em Goiânia-Goiás, no Hospital Araújo Jorge, de 1992 a 1998. Blocos de parafina contendo tecidos tumorais das pacientes foram obtidos dos arquivos do Laboratório de Histopatologia do Hospital Araújo Jorge para a análise imuno-histoquímica. A expressão das proteínas p53 e c-erbB-2 foi avaliada através do complexo da streptoavidina-biotinaimunoperoxidase $(S A B C)$. Para a análise estatística foi utilizado o teste do $c^{2}$, através do programa SPSS. H ouve associação significativa entre as expressões de p53 e c-erbB-2 ( $p=0.02)$. 0 método de Kaplan-M eier foi utilizado para se estimar as curvas de sobrevida e estas foram comparadas através do teste log-rank. D e acordo com os resultados encontrados, os marcadores p53 e c-erbB-2 não mostraram associações significativas com os dados clínico-patológicos das pacientes ou com a sobrevida das pacientes, sugerindo que outros marcadores moleculares devem ser investigados na elucidação da etiopatogenia e evolução do câncer de mama não metastático.

Palavras-chave: neoplasias mamárias; marcadores biológicos de tumor; cirurgia; p53; c-erbB-2.

*Trabalho realizado no Laboratório de Imuno-histoquímica- H ospital Araújo Jorge, Associação deC ombate ao C âncer em G oiás.

${ }^{1} U$ niversidadeF ederal deG oiás, M estrando em Biologia.

${ }^{2}$ M estre em Biologia M olecular, Professora Adjunta da Universidade C atólica de G oiás, Pesquisadora do H ospital Araújo Jorge, Associação de Combate ao Câncer do Estado de G oiás.

${ }^{3}$ D outora em Biologia M olecular, Professora Adjunta da U niversidadeFederal de G oiás. Enviar correspondência para E.G.M . UniversidadeFederal deG oiás, D epto deBiologia G eral, Instituto deCiências Biológicas I, Caixa Postal 131; 74001-190 Campus Samambaia, G oiânia, GO - Brasil. Email: momotuk@icb1.ufg.br

Recebido em janero de 2001. 


\begin{abstract}
Breast cancer is the most frequent female cancer in the world, both in terms of incidence and mortality. In Brazil, it is the female neoplasm of highest incidence, being most frequent in the South Region of the country (67\%). Recently, a huge interest in the identification of molecular markers with significant prognostic value in breast cancer has been demonstrated. In this study, both p53 and c-erbB-2 proteins were evaluated in 61 node negative breast cancer patients. These pati ents were diagnosed from 1992 to 1998 at the Araujo Jorge H ospital, Goiânia-Goiás. Paraffinembedded tissues of the patients were obtained from the H istopathology Laboratory and analyzed by immunohistochemistry. The expression of p53 protein and c-erbB-2 were evaluated by streptoavidin-biotin complex (SABC). Statistical analysis was performed using the Chi-Square tet, with SPSS package. N o significant association between p53, c-erbB-2 and clinicopathological features was detected; however, there was a significant association between p53 and c-erbB-2 expression $(p=0.02)$. The Kaplan-M eier survival curves were used to estimate overall survival curves and comparisons weremadeusing log-rank statistics. According to theresults, p53 and c-erbB-2 expression wasnot significantly associated to clinicopathological features or overall survival curves of the patients, suggesting that further markers should be investigated in order to clarify the natural history and development of node negative breast cancer.
\end{abstract}

Key words breast neoplasms, biological tumor markers; surgery; p53; c-erbB-2.

\section{INTRODUÇÃO}

0 câncer de mama é considerado a mais freqüente neoplasia que acomete mulheres em todo o mundo, tanto em termos de incidência quanto de mortalidade. ${ }^{1}$ Distribui-se em praticamente todas as partes do mundo, aparecendo com mais freqüência em alguns países europeus, na América do $\mathrm{N}$ orte e em alguns países sul-americanos, inclusive no Brasil. ${ }^{2} \mathrm{~N}$ a população feminina de Goiânia, a incidência e mortalidade por câncer de mama tem aumentado, apresentando taxas elevadas. O s valores de incidência já superam os de câncer de colo uterino que durante muitos anos representaram o tipo de tumor mais incidente nesta população. ${ }^{3}$

Contudo, diversos critérios morfológicos têm sido utilizados para descrever ou nomear a agressividade de um tumor. D entre estes critérios incluem-se o tipo histológico, o grau de polimorfismo nuclear, a presença ou ausência de resposta inflamatória, o número de mitoses e o comprometimento de vasos sangüíneos e linfáticos, dentre outros. ${ }^{4} \mathrm{~N} 0$ que diz respeito aos tumores de mama, 0 método semi-quantitativo de graduação histológica da malignidade proposto por Bloom e Richardson (1957) enfatiza o índice mitótico, o polimorfismo nuclear e a presença ou não de formação tubular.

Com a utilização das técnicas moleculares, os eventos envolvidos no processo de carcinogênese têm sido gradativamente esclarecidos, resultando na geração de uma série de novas informações que vêm sendo absorvidas pelos oncologistas clínicos, influenciando suas condutas e tomada de decisões. ${ }^{4}$ R ecentemente, tem ocorrido um grande interesse na identificação de marcadores moleculares de valor prognóstico significante, uma vez que al guns tumores com características clínicas indicativas de boa evolução revelam mudanças inesperadas na progressão da doença. ${ }^{6}$

Alguns marcadores são reconhecidos como fatores prognósticos bastante característicos, como o status de receptores hormonais, ${ }^{7}$ marcadores de proliferação celular, tais como a ploidia do D N A e fração $S$, fatores de angiogênese peritumoral, além de produtos protéicos de genes supressores de tumor e oncogenes. ${ }^{6} \mathrm{~A}$ relação entre aspectos clínico-patológicos do câncer de 
mama e mutações no gene p53, avaliadas através de técnicas moleculares, ou seu acúmulo visualizado pela técnica imunohistoquímica, além da expressão de marcadores como o c-erb-B2 (HER-2/neu), tem sido estudada intensamente. ${ }^{8-11}$

O s eventos genéticos encontrados mais freqüentemente associados com as neoplasias humanas são as alterações no gene e na proteína p53.12-17 0 gene p53 localiza-se no cromossomo 17p13, possui aproximadamente $20 \mathrm{~Kb}$ e origina um transcrito primário (mRNA) de $2.8 \mathrm{~Kb} .{ }^{18}$ Estegenefoi descoberto em 1979, sendo proposto inicialmente como um oncogene. ${ }^{12}$ Posteriormente, verificou-se que a atividade oncogênica deste gene dependia de mutações no código de leitura, e queo genenão mutado produzia uma proteína de $53 \mathrm{KDa}$, apresentando uma função de "guardiã do genoma" ao reconhecer danos no DNA e controlar crescimento e morte celular. ${ }^{18}$ D este modo, esta proténa controla a proliferação celular, exercendo um papel fundamental na supressão do desenvolvimento tumoral. ${ }^{12-17}$

U m outro fator bastante estudado em tumores de mama, o oncogenec-erbB-2 (H er$2 /$ neu) localiza-se no cromossomo $17 q 21$ e codifica um receptor glicoprotéico transmembrana denominado p185neu/ p285erbB-2. ${ }^{17,19}$ Aproximadamente 20\%-25\% dos tumores de mama apresentam amplificação deste oncogene, mas os índices aumentam para $40 \%$ quando pacientes linfonodo positivas são incluídas. ${ }^{14}$

A oncoproteína c-erb-B2 funcional é um dímero, sendo classificada como uma glicoproteína transmembrana de $185 \mathrm{KD}$ a, contendo um domínio extracelular de ligação e um domínio de atividade intracelular de tirosina cinase. ${ }^{19} \mathrm{~A}$ expressão aumentada da oncoproténac-erb-B2 acarreta autofosforilação do receptor específico e subseqüente ativação de cinases envolvidas em mecanismos de transdução de sinais, o que eventualmente afeta a transcrição de genes reguladores da progressão do ciclo celular. ${ }^{19}$ Esta superexpressão pode estar associada com pior prognóstico efalta de resposta a determinadas drogas anti-tumorais em pacientes com câncer de mama. ${ }^{20}$

N este trabalho, tanto a proteína $p 53$ quanto 0 produto do oncogene c-erbB-2 fo- ram avaliados em pacientes com câncer de mama sem comprometimento axilar, com 0 intuito de compreender alguns eventos moleculares envolvidos na progressão da neoplasia mamária.

\section{MATERIAL E MÉTODOS}

\section{Grupo de estudo}

0 grupo é composto de 61 pacientes com câncer de mama não metastático, com idades abaixo de 50 anos e que não receberam nenhum tipo de terapia adjuvante antes da cirurgia. As pacientes foram atendidas junto ao Serviço de Ginecologia e $\mathrm{M}$ ama do $\mathrm{H}$ ospital Araújo J orge no período de 1992 a 1998. $D$ ados relativos às pacientes, incluindo nome, idade na época do diagnóstico, tabagismo, atividade profissional, antecedentesfamiliares, e as características tumorais, como tipo histológico e graduação histológica de acordo com Bloom e Richardson, ${ }^{5}$ lado do tumor e tamanho do tumor foram colhidos dos prontuários das respectivas pacientes e anotados em formulários apropriados.

\section{Amostras teciduais}

Blocos de parafina, contendo tecidos das 61 pacientes selecionadas, foram obtidos dos arquivos do Laboratório de $\mathrm{H}$ istopatologia do H ospital Araújo Jorge. A partir de cada bloco, foram obtidos três cortes de $3 \mathrm{~mm}$ de espessura, sendo que dois dos cortes foram colhidos em lâminas previamente preparadas com organossilano para análise imunohistoquímica. Um dos cortes foi utilizado para a confecção de uma lâmina, corada por hematoxilina-eosina (H E) e reavaliada por um patologista.

\section{Análise imuno-histoquímica}

A expressão das proteínas p53 e c-erbB-2 foi avaliada com o auxílio da técnica imunohistoquímica da streptoavidina-biotinaimunoperoxidase. Os cortes de $3 \mathrm{~mm}$ de espessura foram estendidos em lâminas preparadas com adesivo à base de 3aminopropil-trietoxi-silano (Sigma C hemical Co, St Louis, MO USA). Inicialmente, os cortes foram incubados por 24 horas em estufa a $55^{\circ} \mathrm{C}$ e depois desparafinados em três 
banhos dexilol, a $60^{\circ} \mathrm{C}, 55^{\circ} \mathrm{C}$ eà temperatura ambiente, durante 60,30 e 20 minutos, respectivamente. A seguir, os cortes foram hidratados em concentrações decrescentes de etanol, seguidos por lavagens em água corrente. As seções teciduais foram submetidas, a seguir, à recuperação antigênica utilizando-se panela de pressão (calor úmido) em solução de tampão citrato $10 \mathrm{mM} / \mathrm{pH}$ 6.0. ${ }^{21}$ Posteriormente, foi feito o bloqueio da peroxidase tecidual endógena por meio de três passagens de 15 minutos em solução de peróxido de hidrogênio 10 volumes. $E m$ seguida, os cortes foram submetidos à incubação com os anticorpos primários, antip53 (D ako, D 0 -7; 1/100) e c-erbB-2 (D ako, policlonal, 1/600), por 24 horas. Os anticorpos foram diluídos em solução salina fosfato $\mathrm{pH} 7.2$ (PBS) com 1\% de albumina sérica bovina, em câmara úmida a $4^{\circ} \mathrm{C}$. $D$ epois de três lavagens em tampão PBS, os cortes foram incubados com 0 anticorpo secundário de cabra anti-camundongo biotinilado, em solução pronta para uso (D ako; CA, USA). As seções teciduais foram lavadas novamente três vezes em tampão PBS pH 7.2, por 5 minutos. Logo depois, foi aplicado o complexo streptoavidina-biotinaperoxidase em solução pronta para uso ( $D$ ako, CA, U SA), durante 30 minutos em câmara úmida a $37^{\circ} \mathrm{C}$. Para a revelação da reação foi utilizada a solução de diaminobenzidina ( $D$ ako, CA, USA) e tampão salina fosfato $\mathrm{pH}$ $7.2(0.015 \mathrm{~g}$ de diaminobenzidina para cada $25 \mathrm{ml}$ de PBS pH 7.2). A pós a revelação, as lâminas foram lavadas em água corrente e foram coradas em hematoxilina. O s cortes foram desidratados em álcool absoluto por cinco vezes, 2 minutos em cada etapa, depois foram colocados em banhos de xilol por três vezes. As lâminas foram montadas em resina do tipo Entellan (M erck K gaA). Todas estas etapas foram feitas com a utilização de controles positivos, tecidos de carcinoma de mama com padrão de revelação já conhecido para p53 e c-erbB-2.

\footnotetext{
Análise estatística

0 s resultados obtidos dos prontuários das respectivas pacientes, assim como os da análise imuno-histoquímica da proteína p53
}

e da oncoproteína c-erbB-2 foram tabulados em planilhas, constituindo um banco de dados. As pacientes foram divididas em grupos, de acordo com a expressão das proteínas p53 e c-erbB-2, visando a obtenção da curva de sobrevida, calculada pelo método de Kaplan-M eier. ${ }^{22}$ As prováveis diferenças entre estas curvas foram avaliadas pelo teste log-rank, com a utilização do programa SPSS, em 1993. As associações entre as expressões da proteína p53 e da oncoproteína c-erbB-2, com o tamanho dos tumores na palpação, graduação histológica, tipo histológico e outros aspectos clínico-patológicos foram calculadas através do teste do $\lambda^{2}$, a um nível de significância de 5\%.

\section{RESULTADOS}

Aspectos clínico-patológicos do grupo de estudo

As pacientes apresentaram em média, 43 anos de idade ( $D P= \pm 5.16$ ), sendo que 0 diagnóstico dos tumores e a ausência de metástases em linfonodos axilares foram comprovados por análise anatomopatológica. D as 61 pacientes analisadas, 44 (72\%) apresentaram tumores maiores que $3 \mathrm{~cm}$, com predominância do tipo histológico correspondente ao Carcinoma Ductal Infiltrante(CDI), com 57 casos(93\%). 0 grau de diferenciação histológica mais encontrado foi o grau II, perfazendo 60\% (37 casos). Vinte pacientes (33\%) apresentaram recorrência familiar do câncer de mama, 45 (74\%) eram multíparas e 17 (28\%) pacientes eram tabagistas. Foram encontradas recidivas em 18 pacientes $(30 \%)$ e destas, cinco foram a óbito $(28 \%)$.

\section{Expressão imuno-histoquímica}

A expressão da proteína p53 foi considerada positiva, em células com reação restrita ao núcleo e a expressão da oncoproteína c-erbB2 foi detectada em células com reação de membrana, ambas de coloração acastanhada, 0 suficiente para a diferenciação entre células positivas e negativas.

D as 61 pacientes analisadas, 27 (44\%) apresentaram imunodetecção da proteína 
p53, 18 (29\%) apresentaram expressão de c-erbB-2 e em 12 pacientes (20\%) foram evidenciadas a expressão dos dois marcadores avaliados.

\section{Análise estatística}

Associações entre p53 e aspectos clínicopatológicos

Possivivis associações entre a imunodetecção da proteína p53 e as características clínicopatológicas descritas foram investigadas através do teste do $\lambda^{2}$, a um nível de significância de $5 \%$. N enhuma associação significativa entre a expressão de p53 e tais características pode ser evidenciada, como observado na Tabela 1.

Associações entre c-erbB-2 e aspectos clínicopatológicos

Associações entre a imunodetecção da oncoproteína c-erbB-2 e os dados clínicopatológicos das pacientes também foram investigados (Tabela 2). N enhuma associação significativa entre a expressão de c-erbB-2 e

\begin{tabular}{|c|c|c|c|c|}
\hline \multirow[t]{2}{*}{ Parâmetros } & \multicolumn{3}{|c|}{ Imunodetecção de p53 (\%) } & \multirow[t]{2}{*}{ Valor $P$} \\
\hline & - & + & Total & \\
\hline \multicolumn{5}{|c|}{ A - Tamanho do Tumor } \\
\hline$<3 \mathrm{~cm}$ & $7(21 \%)$ & $10(37 \%)$ & $17(28 \%)$ & 0,15 (NS) \\
\hline$>3 \mathrm{~cm}$ & $27(79 \%)$ & $17(63 \%)$ & $44(72 \%)$ & \\
\hline \multicolumn{5}{|c|}{ B - Graduação Histológica } \\
\hline | & $3(9 \%)$ & $3(11 \%)$ & $6(10 \%)$ & 0,79 (NS) \\
\hline$\|$ & $23(68 \%)$ & $16(59 \%)$ & $39(64 \%)$ & \\
\hline III & $8(23 \%)$ & $8(30 \%)$ & $16(26 \%)$ & \\
\hline \multicolumn{5}{|c|}{ C - Tipo Histológico } \\
\hline CDI & $31(91 \%)$ & $25(93 \%)$ & $56(92 \%)$ & 0,84 (NS) \\
\hline Outros & $3(9 \%)$ & $2(7 \%)$ & $5(8 \%)$ & \\
\hline \multicolumn{5}{|c|}{ D - História Familiar } \\
\hline Presença & $8(23 \%)$ & $9(33 \%)$ & $17(28 \%)$ & 0,39 (NS) \\
\hline Ausência & $26(77 \%)$ & $18(67 \%)$ & $44(72 \%)$ & \\
\hline \multicolumn{5}{|l|}{ E - Recidivas } \\
\hline Presença & $11(32 \%)$ & $7(26 \%)$ & $18(30 \%)$ & 0,58 (NS) \\
\hline Ausência & $23(68 \%)$ & $20(74 \%)$ & $43(71 \%)$ & \\
\hline
\end{tabular}

NS: não significativo/CDI: carcinoma ductal infiltrante

Tabela 2. Imunodetecção de c-erbB-2 e parâmetros clinicopatológicos de pacientes com câncer de mama não metastático.

\begin{tabular}{|c|c|c|c|c|}
\hline \multirow[t]{2}{*}{ Parâmetros } & \multicolumn{3}{|c|}{ Imunodetecção de c-erbB-2 (\%) } & \multirow[t]{2}{*}{ Valor $P$} \\
\hline & - & + & Total & \\
\hline \multicolumn{5}{|c|}{ A - Tamanho do Tumor } \\
\hline$<3 \mathrm{~cm}$ & $13(30 \%)$ & $4(22 \%)$ & $17(28 \%)$ & 0,52 (NS) \\
\hline$>3 \mathrm{~cm}$ & $30(70 \%)$ & $14(78 \%)$ & $44(72 \%)$ & \\
\hline \multicolumn{5}{|c|}{ B - Graduação Histológica } \\
\hline 1 & $6(14 \%)$ & $0(0 \%)$ & $6(10 \%)$ & 0,24 (NS) \\
\hline$\|$ & $26(60 \%)$ & $13(72 \%)$ & $39(64 \%)$ & \\
\hline III & $11(26 \%)$ & $5(28 \%)$ & $16(26 \%)$ & \\
\hline \multicolumn{5}{|c|}{ C - Tipo Histológico } \\
\hline CDI & $38(88 \%)$ & $18(100 \%)$ & $56(92 \%)$ & 0,30 (NS) \\
\hline Outros & $5(12 \%)$ & $0(0 \%)$ & $5(8 \%)$ & \\
\hline \multicolumn{5}{|c|}{ D- História Familiar } \\
\hline Presença & $13(30 \%)$ & $4(22 \%)$ & $17(28 \%)$ & 0,52 (NS) \\
\hline Ausência & $30(70 \%)$ & $14(88 \%)$ & $44(72 \%)$ & \\
\hline \multicolumn{5}{|l|}{ E-Recidivas } \\
\hline Presença & $15(35 \%)$ & $3(17 \%)$ & $18(30 \%)$ & 0,15 (NS) \\
\hline Ausência & $28(65 \%)$ & $15(83 \%)$ & $43(70 \%)$ & \\
\hline
\end{tabular}

N S: não significativo/CDI: carcinoma ductal infiltrante 
os dados clínico-patológicos das pacientes foi verificada.

Associações entre as expressões das proteínas cerbB-2 e p53

As expressões das proteínas p53 e c-erbB2 foram comparadas, através do teste do $\lambda^{2}$, sendo detectada uma associação significativa $(p \varangle 0.05)$ entre a imunodetecção de c-erbB-2 e da proteína p53 (Tabela 3).

\section{Curvas de sobrevida}

Curvas de sobrevida, de acordo com 0 método proposto por Kaplan e $M$ eier $^{22}$ foram confeccionadas visando observar 0 valor prognóstico dos dois marcadores analisados. 0 acompanhamento das 61 pacientes foi realizado durante 36 meses após os diagnóstico. As pacientes que não retornaram ao serviço de ginecologia e mama do $\mathrm{H}$ ospital Araújo Jorge no tempo previsto foram excluídas desta análise (censuradas).

As 27 pacientes $p 53$ positivas tiveram uma sobrevida média de 33 meses (IC 95\%) e ao final dos 36 meses de acompanhamento, $76 \%$ das pacientes estavam vivas. Com relação às pacientes $p 53$ negativas ( $n=34$ ), $82 \%$ estavam vivas no final do acompanhamento, apresentando uma sobrevida média de 33 meses (IC 95\%). (Figura 1)

Apesar da diferença existente entre os índices de sobrevida observados para as pacientes $p 53$ positivas e negativas vivas, $76 \%$ e $82 \%$, respectivamente, 0 teste estatístico

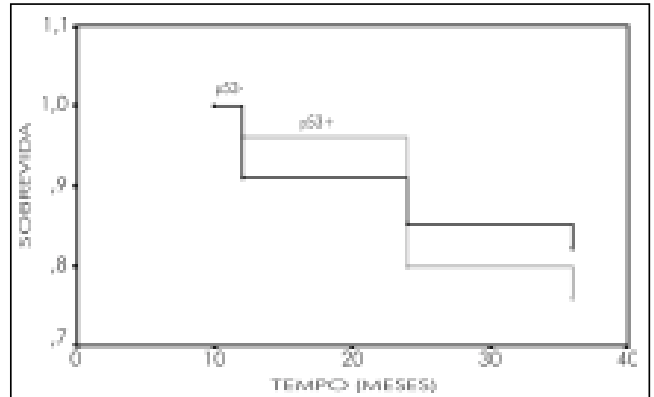

Figura 1. Curva de sobrevida das 61 pacientes com câncer de mama não metastático, de acordo com a express̃o da proténa p53. log-rank, não detectou diferenças significativas entre estas curvas $(p=0.60)$, observação já registrada por outros autores. ${ }^{23,24}$

As 18 pacientes c-erbB-2 positivas apresentaram, em média, uma sobrevida de 36 meses (IC 95\%). No final do tempo de acompanhamento, $94 \%$ das pacientes estavam vivas (Figura 2). Apenas 01 (5\%) paciente, com super-expressão deste marcador, apresentou recidiva.

As 43 pacientes c-erbB-2 negativas apresentaram uma sobrevida média de 32 meses (IC 95\%), sendo que $73 \%$ destas pacientes estavam vivas no final dos 36 meses de acompanhamento (Figura 2) e $11(25 \%$ dos casos) apresentaram recidivas. Em contraste com outros trabalhos s $^{25,26}$ as pacientes deste estudo que não expressaram c-erbB-2, tiveram menores índices de sobrevida (73\%) do que pacientes com super-expressão deste marcador (94\%), entretanto, a análise estatística não evidenciou diferenças significativas entre estas curvas ( $p=0.06)$. O s dois marcadores analisados não foram detectados em 28 pacientes (46\%), que apresentaram uma sobrevida média de 32 meses (IC 95\%). A imunodetecção dos dois marcadores foi evidenciada em $20 \%$ dos casos $(n=12)$, e ao final do período de acompanhamento (36 meses), 92\% destas pacientes não apresentavam evidências da doença (Figura 3). 0 curto prazo de acompanhamento destas pacientes pode ter contribuído para tais achados, uma vez que a

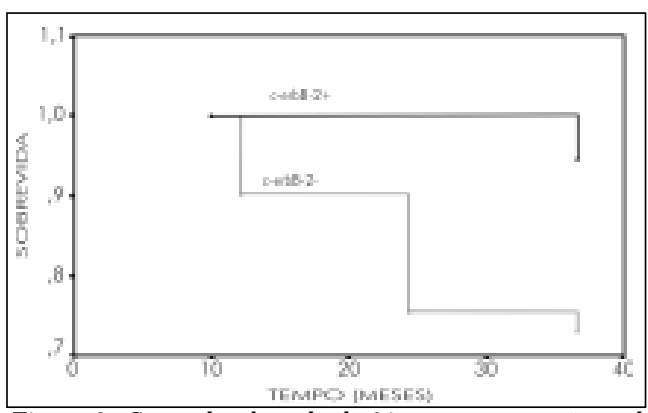

Figura 2. Curva de sobrevida de 61 pacientes com câncer de mama não metastático de acordo com a expressão de c-erbB-2.

Tabela 3. Imunodetecção de p53 e super-expressão de c-erbB-2 em pacientes com câncer de mama não metastático.

\begin{tabular}{lcccc} 
& \multicolumn{3}{c}{ Imunodetecção de p53 (\%) } & Valor P \\
\cline { 2 - 3 } & & + & Total & \\
c-erbB-2 & $28(82 \%)$ & $15(55 \%)$ & $43(70 \%)$ & $0,02(S)$ \\
Expressão negativa & $6(18 \%)$ & $12(45 \%)$ & $18(30 \%)$ & \\
Expressão positiva & & & \\
\hline
\end{tabular}

S: significativo 


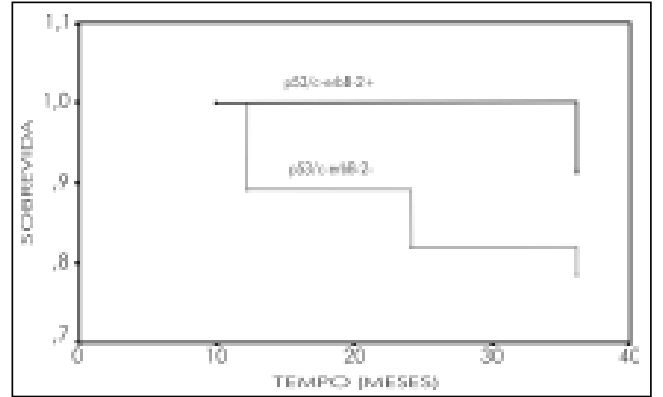

Figura 3. Curva de sobrevida de 61 pacientes com câncer de mama não metastático de acordo com a expressão dos dois marcadores analisados, p53 e c-erbB-2.

presença de recidivas em pacientes com câncer de mama pode envolver períodos mais longos, de pelo menos 10 anos. ${ }^{8,9,14,18}$

\section{DISCUSSÃO}

O câncer de mama, apesar das novas estratégias terapêuticas e diagnósticas empregadas, continua sendo um desafio na área médica. Em função de problemas sócioeconômicos e culturais no Brasil, as pacientes quebuscam os serviços públicos de mastologia apresentam na maioria das vezes tumores avançados, o que dificulta o diagnóstico e acarreta tratamentos mais agressivos. Entretanto, uma parcela das mulheres atendidas na rede pública, provavelmente em função das crescentes campanhas de prevenção do câncer de mama, apresenta tumores intermediários, com perfis aparentemente menos agressivos e que demandam a investigação detal hada de todos os aspectos que possam auxiliar na definição do protocolo terapêutico, no sucesso da evolução do quadro e na cura da paciente.

Os fenômenos moleculares que acompanham a carcinogênese, a interpretação e adaptação destas informações vêm sendo estudadas e têm auxiliado os médicos na tomada de decisões. Para melhor se estudar a evolução desta neoplasia e para tratálla mais convenientemente surgiu a necessidade de informações mais detal hadas sobre os fatores capazes de influenciar o desenvolvimento desta doença.

Este trabalho diz respeito a tumores de mama englobados no estágio clínico I, ou seja, carcinomas de mama não metastáticos, sem comprometimento axilar. Geralmente, tais tumores apresentam boa evolução, sendo de bom prognóstico, ocorrendo em pacientes com idades mais avançadas, que apresentam tipos histológicos menos agressivos, receptores hormonais positivos e ausência de história familiar. ${ }^{17}$ Contudo, algumas pacientes apresentando este tipo tumoral evoluem de forma semelhante àquelas que possuem câncer de mama bastante agressivo, daí a necessidade premente de se avaliar outros marcadores que auxiliem na evolução clínica das pacientes. A proximadamente $30 \%$ das pacientes com câncer de mama sem comprometimento axilar morrem devido a esta neoplasia;; assim, marcadores biológicos tais como as proteínas p53 e c-erbB-2 têm sido relacionados com a progressão tumoral, apresentando um valor prognóstico controverso. ${ }^{8,26}$

No presente estudo, a imuno-expressão de dois marcadores biológicos, p53 e c-erbB2 não apresentou correlação com os parâmetros clinico-patológicos das pacientes, como tamanho do tumor, graduação histológica da malignidade, proposta por Bloom e Richardson, ${ }^{5}$ tipo histológico e presença de história familiar. Tumores que expressaram tais marcadores não apresentaram fenótipos mais ou menos agressi vos quando analisados estatisticamente. A precocidade do estágio clínico considerado e a homogeneidade do grupo de estudo em questão podem ter contribuído com os resultados aqui apresentados, apesar de contrariar alguns estudos já publicados. 20,25,26

Como indicado por este e outros estudos realizados em pacientes jovens com câncer de mama sem comprometimento axilar, a expressão de p53, detectada pela técnica imuno-histoquímica, não apresentou valor como marcador prognóstico. 8,23,27,28 A associação entre 0 acúmulo da proteína p53 e a sobrevida destas pacientes também não foi evidenciada. Estes achados estão de acordo com outros trabalhos, ${ }^{8,11,29,30}$ pois o grupo de estudo desta pesquisa foi constituído de pacientes com idades abaixo de 50 anos, sugerindo que a ocorrência desta neoplasia nesta faixa etária pode estar relacionada com eventos genéticos distintos, ainda não elucidados. A grande maioria dos trabalhos que mostram associação da proteína p53 e dados clinico-patológicos de pacientes com câncer de mama, incluem grupos mais 
heterogêneos, com idades avançadas, comprometimento axilar ou até mesmo metástases disseminadas. Além disto, outros métodos de análise são utilizados, como 0 estudo de mutações gênicas, através de técnicas moleculares de análise de DNA.

A técnica de imuno-histoquímica é bastante utilizada neste tipo de estudo por se tratar de um ensaio rápido, simples e capaz de avaliar as características tumorais de maneira clara e eficiente. Entretanto, a análise imuno-histoquímica de p53 apresenta diversas limitações que merecem destaque. Mutações no gene p53, geralmente resultam em proteínas alteradas, que se acumulam no núcleo das células tumorais, sendo facilmente detectadas. ${ }^{31}$ C ontudo, al guns dos anticorpos utilizados são incapazes de discriminar entre os tipos selvagem e mutante da proténa p53, como no caso do anticorpo D 0-7 utilizado neste trabalho. Além disso, aproximadamente $20 \%$ das mutações no gene p53 resultam em proténas truncadas, que não são identificadas pela técnica imuno-histoquímica. ${ }^{18,31} \mathrm{~A}$ interpretação dos resultados desta técnica, em tumores de mama no estágio inicial, pode se tornar ainda mais difícil, devido ao número reduzido de núcleos de células tumorais corados. ${ }^{18}$ Isto pode ocorrer na formação dos primeiros clones mutantes, responsáveis pela progressão tumoral, ou durante 0 acúmulo da própria proteína normal em células não neoplásicas, como resposta a agentes genotóxicos (luz UV), hipóxia ou por outras mudanças biológicas do ambiente celular. ${ }^{31}$

Q uanto ao c-erbB-2, o outro marcador analisado neste trabalho, também não foram demonstradas associações entre a superexpressão desta oncoproteína com os parâmetros clínicos clássicos das pacientes. Diversos estudos detectaram a superexpressão de c-erbB-2 em 31\% dos casos analisados, 32 outros em $17 \%$ de pacientes com câncer de mama (27\%). Estudos mais recentes evidenciaram a super-expressão de c-erbB-2 em 10\% e 33\%, de tumores de mama do tipo ductal infiltrante, respectivamente. ${ }^{8,20} \mathrm{D}$ e uma maneira geral, a super-expressão de c-erbB-2 pode ser encontrada em $10 \%$ a $40 \%$ dos tumores de mama não metastáticos, e no presente estudo, 18 pacientes (29\%) apresentaram super- expressão de c-erbB-2. N este trabalho, a imunodetecção de p53 esteve associada com a super-expressão da oncoproteína c-erbB-2, como evidenciado por outros grupos $(10,14,17,33)$, principalmente em pacientes jovens, com câncer de mama invasivo.

0 s resultados deste trabalho sugerem que a presença ou ausência dos marcadores p53 e c-erbB-2 não refletiram aspectos histopatológicos mais ou menos agressivos deste grupo de estudo. Isto pode ser explicado pelas características do próprio grupo, formado por pacientes relativamente jovens, média de idade de 43 anos. Além disto, os parâmetros clinicopatológicos analisados foram bastante homogêneos, sendo que a maioria dos tumores apresentou grau nuclear II (64\%), o tipo histológico predominante foi o CDI (92\%) e o tamanho dos tumores foi em média $3 \mathrm{~cm}$. A homogeneidade deste grupo de pacientes foi a principal razão para a investigação de fatores que pudessem auxiliar na maneira de evolução clínica das mesmas. O s achados deste e de outros grupos podem indicar a necessidade de se avaliar outros parâmetros, como a associação entre a imunodetecção da proteína p53 e a presença de mutações no gene p53, ou ainda a associação dos dois marcadores analisados, p53 e c-erbB-2, com outros fatores prognósticos descritos.

\section{REFERÊNCIAS BIBLIOGRÁFICAS}

1. Persson I, Bergstrom R, Sparen P, Thorn M , Adami $\mathrm{H}$ 0. Trendsin breast cancer incidencein Sweden 1958-1988 by timeperiod and birth cohort. Br J Cancer 1993;68:1247-53.

2. Instituto $\mathrm{N}$ acional deCâncer (Brasil). Estimativa deincidênciaemortalidade por câncer demama no Brasil. Rio deJ aneiro: IN CA; 1999.

3. Associação de Combate ao $C$ âncer em Goiás (Brasil). Registro de câncer debase populacional deGoiânia. Goiânia; 1997.

4. PaesR. M arcadoresprognósticosem neoplasias mamárias. In: Wakamatsu $A$, Simões $A B$, Kanamura CT, Pinto GA, M etzel L, Vassalo J, et al. M anual de Imuno-histoquímica. São Paulo: SociedadeBrasileira dePatologia; 1995. p. 62-9. 
5. Bloom H , Richardson W. H istological grading and prognosis in breast cancer. $\mathrm{Br} J$ Cancer 1957;9:359-77.

6. PhilipsK, AndrulisL, Goodwin P. Breast carcinoma arising in carriers of mutation sin BRCA1 or BRCA2: arethey prognostically different?J Clin Oncol 1999;17:3653-63.

7. American Society of Clinical O ncology (ASCO). 1997 U pdate of recommendationsfor the use of tumor markers in breast and colorectal cancer. J Clin O ncol 1998;16:793-5.

8. Reed W, H annisdal E, Boehler P, G undersen S, $\mathrm{H}$ ost $\mathrm{H}, \mathrm{N}$ esland $\mathrm{J}$. The prognostic value of p53 and c-erb b-2 immunostaining is overrated for patients with lymph node negative breast carcinoma. C ancer 2000;88:804-13.

9. SchmittFC, SoaresR, CirnesL, SerucaR. p53 in breast carcinomas: association between pres ence of mutation and immunohistochemical expression using a semiquantitative approach. Pathol Res Pract 1998;194:815-9.

10. Slooten V, Vivjer V, Borresen A. M utationsin exons 5-8 of the p53 gene, independent of their typeand location, areassociated with increased apoptosisand mitosisin invasive breast carcinoma. J Pathol 1999;189:504-13.

11. G entileM , Jungestrom B, O Isen KE, Soderkvist P, W ingren S. p53 and survival in early onset breast cancer: analysis of gene mutations, loss of heterozigosity and protein accumulation. Eur J Cancer 1999;35:1202-7.

12. Levine AJ, M omand J, Finlay CA. The p53 tumor suppressor gene. $N$ ature 1991;351: 453-6.

13. M ilner JA. Conformation hypothesis for the suppressor and promoter functions of $\mathrm{p} 53$ in cell growth and in cancer. Proc $\mathrm{N}$ atl Acad Sci USA 1991;245:85-158.

14. H an S, Yun I, N oh D, ChoeK, Song S, Chi J. Abnormal expression of four molecular markers represents highly aggressive phenotype in breast cancer. I mmunohistochemical assay of p53, nm23, erbB-2, and cathepsin D protein. J Surg O ncol 1997;65:22-7.

15. BernesE, Staveren I, Look M , Smid M , Klijn J, Foekens). M utation sin residues of $T$ P53 that directly contact D N A predict poor outcomein human primary breast cancer. $\mathrm{Br} J \mathrm{C}$ ancer 1998;77:1130-6.

16. Iacopetta B, Grieu F, Powell B, Soong R, M ccaul $K$, Seshadri R. Analysis of p53 genemutation by polymerasechain reaction singlestrand conformation polymorphism provides indepen- dent prognostic information in nodenegative breast cancer. Clin C ancer Res 1998;4:1597602.

17. Fiche M, Avet-Loiseau H, H eymann M F, M oussaly F, Digabel C, Joubert M, et al. Genetic alterations in early-onset invasive breast carcinomas: correlation of c-erbB-2 amplification detected by fluorescence in situ hybridization with p53 accumulation and tumor phenotype. Int J Cancer 1999;84:511-5.

18. SidranskyD , H ollstein M . Clinical implications of thep53 gene. Ann Rev M ed 1996;47:285-301.

19. Leitzel K, Teramoto Y, Konrad K. Elevated serum c-erbB-2 antigen levelsand decreased responseto hormonetherapy of breast cancer. J Clin O ncol 1995;13:1129-35.

20. Sharma BK, Ray A, Kaur S, G upta S. Immunohistochemical co-expression of c-erbB-2/N eu oncoprotein, altered tumor suppressor (p53) protein, EGF-R and EM A in histological subtypes of infiltrating duct carcinoma of the breast. Indian J Exp Biol 1999;37:223-7.

21. N orton AJ, Jordan S, Yeomans P. Brief, high temperature heat denaturation (pressure cooking): a simpleand effectivemethod of antigen retrieval of routinely processed tissues. J Pathol 1994;173:371-9.

22. Kaplan EL, M eier P. N onparametric estimation from incompleteobservations. J Am Stat Assoc 1958;53:457-81.

23. Bianchi S, Calzolari A, Vezzosi V, Zampi G, Cardona G, Cataliotti L, et al. Lack of prognosis value of p53 protein expression in nodenegative breast cancer. Tumori 1997;83:669-72.

24. Colomer R. Relationship of tissueand circulating c-erbB-2 with prognosisin primary breast cancer. Symp Proc 1998;105-8.

25. Cobleigh M. M ore than one way to look for H ER2. Clin Pathol Today 1999;13:46.

26. Stoll BA. Premalignant breast lesions: rolefor biological markersin predicting progression to cancer. Eur J Cancer 1999;35:693-7.

27. Lukas\}, N iu N , Press M f. p53 mutationsand expression in breast carcinoma in situ. Am J Pathol 2000;156:183-91.

28. Isola J, Visakorpi T, H olli K, Kallioniemi O P. Association of overexpression of tumor suppres sor protein p53 with rapid cell proliferation and poor prognosis in nodenegativebreast cancer patients. J N atl C ancer Inst 1992;84:1109-14.

29. Porter PL, M aloneK, H eagerty P. Expression of cell-cycle regulators p27kipl and cyclin E, aloneand in combination, correlate with sur- 
vival in young breast cancer patients. $\mathrm{N}$ ature 1997;3:222-5.

30. Bertheau P, Steinberg S, M erino M . c-erbB-2, p53 and nm23 gene product expression in breast cancer in young women: immunohistochemical analysisand clinicopathological correlation. H um Pathol 1998;29:323-9.

31. Pharoah PDP, D ay NE, Caldas C. Somatic mutations in the $p 53$ gene and prognosis in breast cancer: a meta- analysis. $\mathrm{Br} J \mathrm{C}$ an- cer1999;80:1968-73.

32. Lipponen P,Ji H , AaltomaS, Syrjanen S, Syrjanen K. p53 protein expression in breast cancer as related to histopathological characteristics and prognosis. Int J C ancer 1993;55:51-6.

33. Shimizu C, Fukutomi T, TsudaH , TanakaAkashi $\mathrm{S}$, WatanabeT, Sugihara K. c-erbB-2 protein overexpression and p53 immunoreaction in primary and recurrent breast cancer.J Surg $0 \mathrm{ncol}$ 2000;73:17-20. 